\title{
DESIGN RESISTANCE OF STAINLESS-STEEL FILLET WELDS
}

\author{
N. Feber*, M. Jandera**, L. Forejtová ${ }^{* * * *}$
}

\begin{abstract}
Welded joint strength depends on the correlation factor $\beta_{w}$, which should be taken 1.0 for all stainless-steel families (according to Eurocode 3 (EN 1993-1-4, 2006)). The aim of this study is to investigate the strength and failure mode of the welded stainless-steel joints to determine the value of the correlation factor $\beta_{w}$ for austenitic grade EN 1.4301 based on experiments. The experiments investigation consists of tensile tests of two plates (15 mm thick) connected by four longitudinal fillet welds. The load was applied parallel to the weld causing only shear stress in the fillet weld. Every specimen was tested to investigate the strength, strain and failure mode.
\end{abstract}

Keywords: Correlation factor, stainless steel, fillet weld.

\section{Introduction}

Stainless steel structures are increasingly used in the building industry due to their corrosion resistance, aesthetic appearance, and other favorable properties. It is load bearing material which combines good mechanical properties with excellent corrosion performance, superior ductility and strain hardening characteristic. In fact, the corrosion resistance is the ability of the steel to form a thin, compact, impermeable, and renewable passivating layer on the surface, which gives these steel grades the resistance to electrochemical corrosion in oxidation environment. This layer is caused by chromium addition (it is necessary for the steel to contain at least $10.5 \%$ of the chromium alloy).

Furthermore, both open and hollow cross-sections are made of stainless steel, nevertheless, those sections are mostly welded. Hence, it is important to investigate the weldability and strength of welded connection. Various studies show that most of the stainless-steel grades have very good weldability by almost all commonly used welding methods (Mathers, 2019).

This paper is focused on the load-bearing capacity of the stainless-steel welded joints. The aim of this work is to determine the value of the correlation coefficient based on experiments and existing analytical formulae.

\section{Research on the strength of fillet welds}

The weldability of high-alloy stainless steels depends on their structure, which is related to the chemical composition. Most stainless steels are materials with very good weldability, but it is necessary to choose the welding method and the procedure correctly regarding their structure. The choice of additional materials and protection of the welding also plays a major role. Generally speaking, the additional material should have the same or very similar chemical composition as the basic material.

It is important to mention that the main disadvantage of the austenitic stainless steel is susceptibility to intergranular corrosion, which might lead to hot-cracking (in the case of increasing contents of elements

Ing. Nina Feber, Ph.D. student: Czech Technical University in Prague, Faculty of Civil Engineering, Thakurova 7; 160 00, Prague, CZ, nina.feber@fsv.cvut.cz

** doc. Ing. Michal Jandera, Ph.D.: Czech Technical University in Prague, Faculty of Civil Engineering, Thakurova 7; 160 00, Prague, CZ, michal.jandera @ fsv.cvut.cz

**** Ing. Lucie Forejtová, Ph.D. student: Czech Technical University in Prague, Faculty of Mechanical Engineering, Technická 4 16607 Prague, CZ, lucie.forejtova@fs.cvut.cz 
$\mathrm{S}, \mathrm{P}, \mathrm{Si}, \mathrm{Ti}, \mathrm{Nb}$ in the structure). It occurs owning the degradation of grain boundaries by $\mathrm{Cr}$. (Ogawa \& Tsunetomi, 1982) (Whillock \& Dunnett, 2004). However, several methods have been used to prevent or minimalize the intergranular corrosion of austenitic stainless steel. For instance, welding without preheating (maximal thermal input up to $15 \mathrm{~kJ} / \mathrm{cm}$ and interpass temperature up to $150^{\circ} \mathrm{C}$, i.e. reduce the heat input as much as possible) or adding strong stabilizing elements such as niobium or titanium in the stainless steel.

According to valid Eurocode 3 Design of steel joints (EN 1993-1-8, 2005) the predicted resistance of the fillet weld is sufficient in Formula 1 and 2 are both satisfied.

$$
\begin{gathered}
\sigma_{w, E d}=\sqrt{\sigma_{\square}^{2}+3 \cdot\left(\tau_{\square}^{2}+\tau_{I I}^{2}\right)} \leq \frac{f_{u}}{\beta_{w} \cdot \gamma_{M 2}} \\
\sigma_{\square} \leq \frac{0.9 \cdot f_{u}}{\gamma_{M 2}}
\end{gathered}
$$

where: $f_{u}$ is the ultimate tensile strength of the weaker part of the two base metals; $\beta_{w}$ is the correlation factor; $\sigma_{\square}$ is the normal stress perpendicular to the weld throat plane; $\tau_{\square}$ is the shear stress perpendicular to the weld throat axis; $\tau_{I I}$ is the shear stress parallel to the weld throat axis; $\gamma_{M 2}$ is the partial safety factor for the connection resistance.

As can be seen from Formula 1, the fillet weld capacity is affected by correlation factor $\beta_{w}$. In practice, the calculation procedure for stainless steel weld capacity is almost the same as for carbon steel, namely the von Mises stress in the weld (see Formula 1) comparison with the ultimate design resistance. Correlation factor $\beta_{w}$ for carbon steel vary between 0.8 and 1.0 depending on the steel grade (see Tab. 1), for stainless steels grades should be assumed as 1.0. In the work "Experimental Study of the Strength of Stainless Steel Fillet Welds" (Fortan, Dejans, Debruyne, \& Rossi, 2018) was proved that the average overdesign of welded stainless steel joints is $27 \%$ for transverse welds and $12 \%$ for longitudinal welds. It follows, that the existing design rules need to be updated and improved.

\begin{tabular}{|c|c|c|c|c|}
\hline \multicolumn{2}{|c|}{ Steel grade } & S235 & S355 & $1.4301^{21}$ \\
\hline$\overline{f_{y}}$ & [MPa] & 235 & 355 & 210 \\
\hline$\overline{f_{u}}$ & [MPa] & 360 & 490 & 520 \\
\hline$\beta_{w}$ & {$[-]$} & 0.8 & 0.9 & 1 \\
\hline$f_{u} /\left(\beta_{w} \cdot \gamma_{M 2}\right)$ & [MPa] & 360 & 436 & 416 \\
\hline
\end{tabular}

Tab. 1 : Comparison of strengths and correlation factors of materials

Also, a series of experimental studies on the strength of welded joints in stainless steel constructions (Yang, et al., 2017) was carried out on samples of round bars. Six tests with transverse weld and five samples with longitudinal weld were performed to determine the capacity of the welds, mode and the angle of failure. Tensile and bending resistance of the weld provided by the TIG method was examined (Rao \& Deivanathan, 2014). The influence of the TIG method on austenitic steel joints was described in (Niagaj, 2006).

\section{Experimental Investigation}

\subsection{Welding Process and Procedure}

For the experiments carried out for this work, chromium-nickel austenitic steel (AISI 304 or EN 1.4301) has been chosen, which contains $17-19 \% \mathrm{Cr}, 8-10.5 \% \mathrm{Ni}$ and less than $0.08 \% \mathrm{C}$. Generally speaking, that is the most common stainless steel grade widely used in chemical, medical, gastronomy, machinery industry as well as in civil engineering. This material is particularly convenient for building structures due to its excellent material properties, such as being non-magnetic; having high strength, high ductility and improved corrosion resistance (in such surroundings as water, weak alkalis, weak acids, and the city's atmosphere), and excellent forming properties. 
For purpose of this study, samples were welded manually (see Fig. 1) using the TIG method (i.e. Method 141 according to Standard (EN ISO 4063, 2001)) with the additional material OK AUTROD 316LSi on diameter of $1 \mathrm{~mm}$, which has the most suitable chemical composition of the resulting metal for the following experiments, as it can be seen in Tab. 2.

Tab. 2 : Chemical composition of welding material (http://www.esab.cz, 2019)

\begin{tabular}{ccccccc}
\hline $\mathrm{Mn}[\%]$ & $\mathrm{Mo}[\%]$ & $\mathrm{Cu}[\%]$ & $\mathrm{C}[\%]$ & $\mathrm{Si}[\%]$ & $\mathrm{Ni}[\%]$ & $\mathrm{Cr}[\%]$ \\
\hline 1.8 & 2.6 & 0.12 & 0.01 & 0.9 & 12.2 & 18.4 \\
\hline
\end{tabular}

Tab. 3 : Mechanical properties in tensile (http://www.esab.cz, 2019)

\begin{tabular}{ccc}
\hline Tensile strength $\mathrm{R}_{\mathrm{m}}[\mathrm{MPa}]$ & Yield strength $\mathrm{R}_{\mathrm{e}}[\mathrm{MPa}]$ & Extension A [\%] \\
\hline $440-560$ & $340-440$ & $26-37$
\end{tabular}
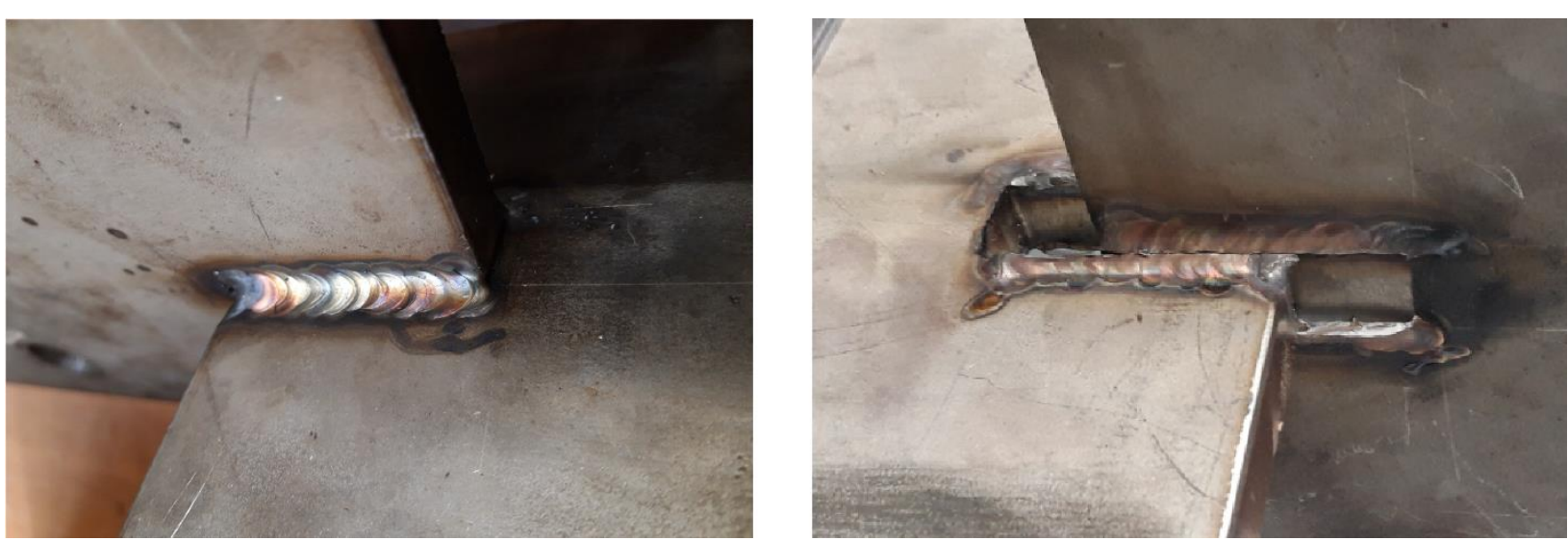

Fig. 1 Stainless steel plates welded by the TIG method (left), typical failure mode (right).

\subsection{Test Programme}

In the course of the work, 5 tensile welding tests of stainless-steel plates (1.4301 grade) will be performed. Each sample consists of two plates (of size 250x140mm, $15 \mathrm{~mm}$ thick) connected by four longitudinal filler welds of $3 \mathrm{~mm}$ throat thickness and $50 \mathrm{~mm}$ length. As was mentioned, welding is done manually using the TIG method with the OK AUTOD 316LSi additional material from ESAB (http://www.esab.cz, 2019). The specimens were bolted to jigs designed for this purpose (see Fig. 2). The tests were performed in a tensile device with a maximum capacity of $300 \mathrm{kN}$ (predicted strength according to Eurocode 3 (EN 1993-1-4, 2006) of the welded connection is $\left.F_{\text {pred }}=144.107 \mathrm{kN}\right)$. The load was applied quasi-statically with speed $0.462 . \mathrm{mm} / \mathrm{min}$. The specimens were loaded by axial force causing the shear stress parallel to the weld throat axis.
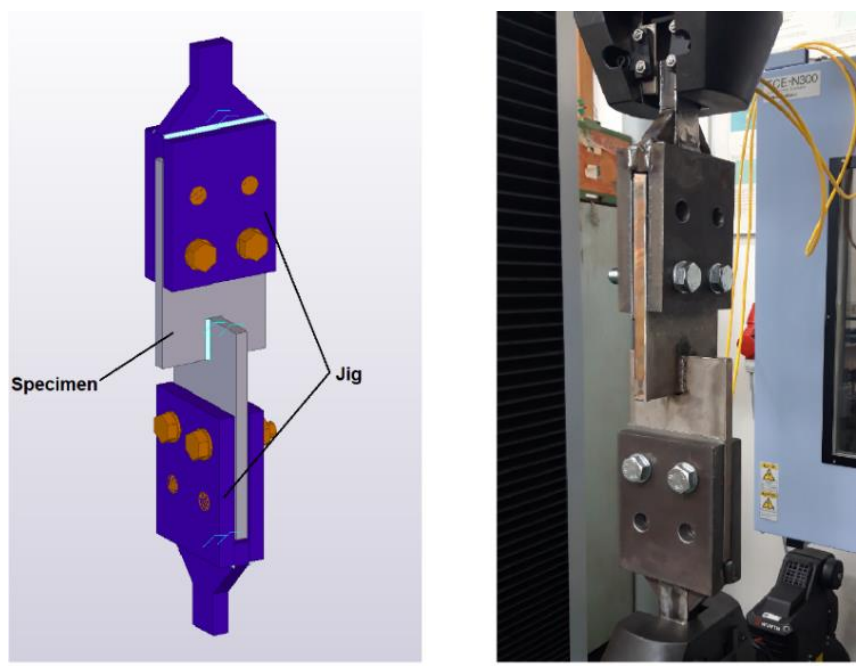

Fig. 2 : The test setup 
The results of the experiments are shown in Tab. 4. By measuring the weld throat over the whole length of the weld, the average volume is considered in the evaluation of the strength. For purpose of evaluation, the partial safety factor $\gamma_{M 2}$ was taken as 1.0. Besides, the ultimate strength of the base material $\left(f_{u}=\right.$ $599 \mathrm{MPa}$ ) was determined from three coupons, which were cut in the same direction as welded specimen were tested in tension.

Tab. 4 : Overview of the test results

\begin{tabular}{ccccccc}
\hline Name & $\mathrm{a}_{\mathrm{w}}$ & $1_{\mathrm{w}}$ & $\mathrm{A}_{\mathrm{w}}$ & $\mathrm{F}_{\text {exp }}$ & $\beta_{\mathrm{w}}$ & $\mathrm{F}_{\text {exp }} / \mathrm{F}_{\text {pred }}$ \\
\hline & {$[\mathrm{mm}]$} & {$[\mathrm{mm}]$} & {$\left[\mathrm{mm}^{2}\right]$} & {$[\mathrm{N}]$} & {$[-]$} & {$[-]$} \\
\hline CS01 & 3.0648 & 48.21 & 591.1 & 247972.90 & 0.824 & 1.721 \\
\hline CS02 & 2.5842 & 47.72 & 493.3 & 228714.30 & 0.745 & 1.587 \\
\hline CS03 & 3.1222 & 47.86 & 597.7 & 247972.90 & 0.833 & 1.721 \\
\hline CS05 & 3.2933 & 49.875 & 657.0 & 265910.30 & 0.854 & 1.845 \\
\hline CS06 & 3.1304 & 49.13625 & 615.3 & 256310.80 & 0.830 & 1.779 \\
\hline
\end{tabular}

\section{Conclusion}

The correlation factor has an important influence on the designed capacity of the stainless steel welded joints. The resulting correlation factor is $\beta_{w}=0.904$, which was determined statistically based on 5 tests. For those specimens, an average experimental-to-predicted strength ratio 1.73. Based on investigation herein, it can be said that the relevant approach in Eurocode (EN 1993-1-4, 2006) leads to slightly conservative design of welded stainless steel joints.

\section{Acknowledgement}

This study was performed with support of TA ČR (TJ01000045).

\section{References}

EN 1993-1-4. (2006). Eurocode 3: Design of Steel Structures - Part 1-4: General Rules - Supplementary Rules for Stainless Steel. Brussels: European Commission for Standardization (CEN).

EN 1993-1-8. (2005). Eurocode 3: Design of steel structures - Part 1-8: Design of joints. Brussels: European Committee for Standardization (CEN).

EN ISO 4063. (2001). Welding and allied processes - Nomenclature of processes and reference numbers. Brusel: European Committee for Standardization (CEN).

Fortan, M., Dejans, A., Debruyne, D., \& Rossi, B. (2018). Experimental Study on the Strength of Stainless Steel Fillet Welds. International Conference on Experimental Mechanics, 1-6.

http://www.esab.cz. (2019). OK AUTROD 316LSi. Retrieved 02 2, 2019

Mathers, G. (2019). Welding of austenitic stainless steel. Retrieved 01 31, 2019, from The Welding Institute: https://www.twi-global.com/

Niagaj, J. (2006). Use of A-TIG method for welding of titanium, nickel, their alloys and austenitic steels. Welding International, 516-520.

Ogawa, T., \& Tsunetomi, E. (1982). Hot Cracking Susceptibility of Austenitic Stainless Steels. Welding research supplement, 82-93.

Rao, A., \& Deivanathan, R. (2014). Experimental Investigation for Welding Aspects of Stainless Steel 310 for the Process of TIG Welding. Procedia Engineering(97), 902-908.

Whillock, G. O., \& Dunnett, B. F. (2004). Intergranular corrosion testing of austenitic stainless steels in nitric acid solutions.

Yang, L., Cui, Y., Xuan, W., Li, M., \& Zhang, Y. (2017). Strength of duplex stainless steel fillet welded connections. Journal of Constructional Steel Research(152), 246-260. 